\title{
MRI of trigeminal zoster
}

\section{RNM do zoster trigeminal}

\author{
Marinos Kontzialis, Carlos A. Zamora
}

A 73 year-old man with remote history of zoster ophthalmicus developed painful vesicular rash inside his mouth after a stressful dental procedure for implants. The rash spread to involve the left side of his face, and he developed severe left-sided stabbing facial pain. On MRI, there was abnormal hyperintense T2 signal (Figure) along the expected course of the nucleus of the spinal tract of the trigeminal nerve ${ }^{1}$, which was consistent with trigeminal zoster $^{2}$. Abnormal signal within the spinal trigeminal nucleus has been described in trigeminal zoster, Ramsay-Hunt syndrome, and in trigeminal neuropathy associated with herpes labialis ${ }^{2,3,4}$.
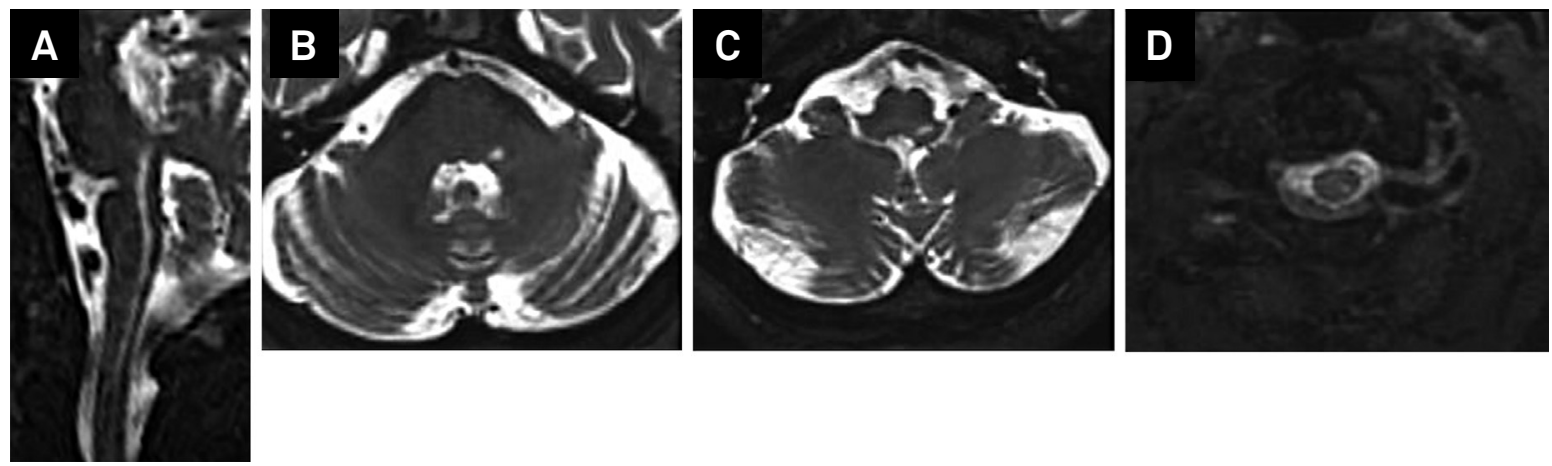

Figure. MRI of trigeminal zoster. (A) Sagittal oblique T2 SPACE image reconstructed from the axial dataset shows abnormal longitudinal hyperintense signal along the expected course of the nucleus of the spinal tract of the trigeminal nerve extending from the lower pons into the dorsal upper cervical cord. (B, C, and D) Axial T2 SPACE images show abnormal hyperintense signal in the expected location of the nucleus in the dorsal pons (B), medulla (C), and upper cervical cord (D) on the left.

\section{References}

1. Brazis PW, Maseu JC, Biller J. Cranial nerve V (the trigeminal nerve). In: Brazis PW, Maseu JC, Biller J. Localization in Clinical Neurology. 6th ed. Philadelphia, PA: Lippincott Williams \& Wilkins; 2011. 305-319.chapter: 9.

2. Oh D, Park SH. Teaching Neurolmages: MRI in Ramsay-Hunt syndrome after trigeminal zoster. Neurology. 2010;74(9):e33. doi:10.1212/WNL.0b013e3181d25b4a
3. Hung CW, Wang SJ, Chen SP, Lirng JF, Fuh JL. Trigeminal herpes zoster and Ramsay Hunt syndrome with a lesion in the spinal trigeminal nucleus and tract. J Neurol. 2010;257(6):1045-6. doi:10.1007/s00415-010-5487-6

4. Umehara T, Oka H, Toyoda C, Mochio S. Pearls and oy-sters: trigeminal neuropathy associated with herpes labialis. Neurology. 2012;79(19):e173-5. doi:10.1212/WNL.0b013e3182735c3d 